\title{
Pacientes em Sala de Espera de Oncologia Pediátrica: Quem São e o que Demandam para a Psicologia?
}

\author{
Shioga, Julia Evangelista Mota; Souza, Bárbara Carvalho de; Alcantara, Tainara \\ Vasconcelos; Lage, Ana Maria Vieira; Maia, Anice Holanda Nunes \\ Universidade Federal do Ceará — juliashioga@hotmail.com
}

Introdução: o estigma que acompanha o câncer infantil faz com que a sua terapêutica seja fator causador de sofrimento psicológico. a falta de informações acerca do processo de adoecimento, a dor causada pelos procedimentos invasivos e pelos efeitos colaterais, a espera, o medo da anestesia e a ansiedade ante o resultado dos exames são alguns fatores causadores de sofrimento psicológico que podem dificultar a adesão ao tratamento por parte dos pacientes. em decorrência disso, a relação dos pacientes com seu tratamento e com o hospital pode se transformar em um processo angustiante e ansiogênico. por esses motivos, justifica-se a realização do projeto Sala de Espera em um serviço de oncologia pediátrica de referência no Estado do Ceará, que proporciona atendimentos psicológicos, por meio de intervenções lúdicas e psicoeducativas, bem como de escuta psicológica. Objetivos: o presente trabalho visa a analisar o perfil e as demandas psicológicas de pacientes que realizaram procedimentos invasivos e seus acompanhantes, buscando também aprimorar as ações de um programa de extensão. Métodos: Realizou-se um estudo exploratório transversal descritivo, no qual foram analisados registros dos atendimentos psicológicos do período de 01.09.2011 a 31.08 .2012 em sala de espera da unidade de procedimentos, com dados sociodemográficos e assistenciais fornecidos pelos acompanhantes. Utilizou-se estatística descritiva com cálculo de frequência relativa e absoluta. Resultados: Foram realizados 505 atendimentos com o seguinte perfil: $41,58 \%$ dos pacientes tem entre 3 a 6 anos de idade, a maioria é proveniente do interior do Estado (62\%). em relação aos exames, $43 \%$ realizaram punção lombar e $28 \%$ mielograma. para $63 \%$, a realização dos procedimentos tinha como objetivo o acompanhamento do tratamento do câncer: $68 \%$ com leucemias e 17\% com tumores sólidos. $55 \%$ desses pacientes são oriundos do serviço de oncologia. dos acompanhantes, $85,05 \%$ são mães entre 19 e 40 anos (72,48\%). 74\% cursaram até o Ensino Médio. dos atendimentos, $41,18 \%$ foram intervenções lúdicas: 55,28\% individuais e 39,90\% com participação do acompanhante. 16,23\% foram escuta psicológica: $62,19 \%$ com acompanhantes; $24,39 \%$ com acompanhantes/pacientes e $13,41 \%$ com pacientes, a maioria com 11 anos ou mais. $3,56 \%$ foram intervenções psicoeducativas e $33,86 \%$ envolveram diversas intervenções em um mesmo atendimento. Conclusções: a partir do estudo, pode-se constatar que os pacientes são predominantemente pré-escolares, em franco desenvolvimento cognitivo e emocional, com neoplasias linfo-hematopoiéticas, submissos a procedimentos invasivos. Demandam intervenções lúdicas para redução da ansiedade e ressignificação de suas experiências. Mães demandam intervenções psicológicas e psicoeducativas para trabalhar angústias e dúvidas. Adolescentes apresentam demanda similar. Os resultados permitem ao programa de extensão focalizar intervenções adequadas à idade, patologias predominantes, cultura e escolaridade dos usuários.

Shioga, Julia Evangelista Mota; Souza, Bárbara Carvalho de; Alcantara, Tainara Vasconcelos; Lage, Ana Maria Vieira; Maia, Anice Holanda Nunes. Pacientes em Sala de Espera de Oncologia Pediátrica: Quem São e o que Demandam para a Psicologia?. In: Anais do Congresso Internacional de Humanidades \& Humanização em Saúde [= Blucher Medical Proceedings, num.2, vol.1]. São Paulo: Editora Blucher, 2014. ISSN 2357-7282

DOI 10.5151/medpro-cihhs-10656 